\title{
Intracranial Hydatid Cyst
}

\author{
Dhulika Dhingra • G. R. Sethi • Mukta Mantan
}

Received: 4 May 2012 / Accepted: 14 March 2013 / Published online: 7 April 2013

(C) Dr. K C Chaudhuri Foundation 2013

To the Editor: A 10-y-old young boy presented to the pediatric casualty with complaints of repeated episodes of generalised tonic clonic seizures. At presentation child was in post ictal state. He was admitted and started on anti convulsant therapy and supportive measures. He regained consciousness and was out of postictal phase within $20 \mathrm{~h}$. Cranial CT scan was ordered which revealed a large non enhancing cystic lesion with no perilesional edema with multiple daughter cysts suggestive of hydatid cyst in the frontal lobe with mass effect (Fig. 1). However clinical examination, chest $\mathrm{X}$ rays and abdominal and chest ultrasound showed no evidence of hydatidosis at other sites. No response was seen to albendazole therapy after which surgical management was planned, which the patient refused.

Hydatid cyst is a zoonotic disease caused by larval stage of Echinococcus granulosis, dog tapeworm which lives in the intestine of the dog. It commonly affects the liver in $75 \%$ of patients and the lung in 15\% [1]. Intracranial hydatid cyst is rare with a reported incidence of $2 \%$ [2]. It is more commonly seen in the area supplied by the middle cerebral artery in both cerebral hemispheres (parietal area is more common followed by frontal region) [3], however the lesion presented here is in the anterior cerebral artery territory. Hepatic and pulmonary hydatidosis is seen in $10-20 \%$ cases of intracranial hyadatidosis [3]. Symptoms largely result due to its size and pressure effects. Intracranial hydatid cysts may be either primary or secondary. Primary cysts result due to direct infestation of brain by the parasite and may not be associated with cysts in other organs. Secondary cysts may result due to spontaneous or traumatic rupture of

D. Dhingra $\cdot$ G. R. Sethi $\cdot$ M. Mantan

Department of Pediatrics, Maulana Azad Medical College,

New Delhi, India

D. Dhingra $(\triangle)$

D-1/66 Janak Puri,

New Delhi 110058, India

e-mail: drdhulika@yahoo.co.in

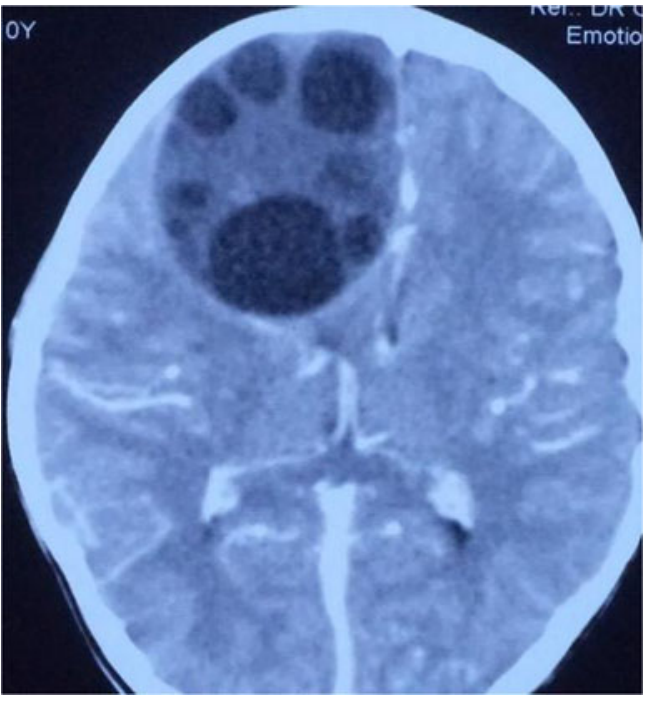

Fig. 1 CECT head of the patient showing well defined non enhancing cystic lesion with multiple daughter cysts without peripheral edema

primary cysts [4]. Treatment of intracranial hydatid cyst is primarily surgical with the aim of in toto removal to prevent recurrences [5].

\section{References}

1. Pedrosa I, Saíz A, Arrazola J, Ferreirós J, Pedrosa CS. Hydatid disease: Radiologic and pathologic features and complications. Radiographics. 2000;20:795-817.

2. Erashin Y, Muthuer S, Guzelbag E. Intracranial hydatid cysts in children. Neurosurgery. 1993;33:219-25.

3. Turgut M. Intracranial hydatidosis in Turkey: Its clinical presentation, diagnostic studies, surgical management and outcome. A review of 276 cases. Neurosurg Rev. 2001;24:200-8.

4. Siraj MU, Haq MU, Imran M. A giant intracranial hydatid cyst excised in toto. Anaesth Pain Intensive Care. 2010;14:112-4.

5. Shukla S, Trivedi A, Singh K, Sharma V. Craniospinal hydatidosis: Report of three cases. J Pediatr Neurosci. 2008;3:146-9. 